\section{You have heard of CONSORT, you have heard of PRISMA. Now, a template for reporting exercise trials (CERT)}

\author{
Karim Khan
}

How should exercise trials be reported? Dr Susan Slade publishes the answer in the free access paper coining the term 'CERT'-Consensus on Exercise Reporting Template (see page 1428). Such pioneering work is not likely to be set in stone for the next decade. Let's hear your feedback via the various channels by which you can engage with BJSM. We revel in criticism, as you know (a quote from the BMJ's Dr Fiona Godlee). It's the way the field advances.

\section{ALSO IN THIS ISSUE}

You'll see that resistance training ameliorates lung function and hypertension in the setting of obese participants. (see page 1438). A second resistance training paper focuses on resistance training for brain health (see page 1443).

Does exercise have a darker side? What about the risk of arthritis in the sportsperson? Excess osteoarthritis among contact sports people has been reported in the past but never with the large amount of data that exist now because of more sophisticated research and researchers (see page 1459).

Correspondence to Dr Karim Khan, The University of British Columbia, Dept of Family Practice, UBC, Centre for Hip Health and Mobility, Vancouver, BC, Canada V6T 1Z3; karim.khan@ubc.ca
Concussion may have more sequelae than has been considered. The Concussion in Sport Group met in Berlin late in October to hash out the 2017 Concussion in Sport Group Guidelines. Science popularizer, Professor Paul Zehr takes an unconventional approach to knowledge translation (see page 1481). The term 'caped crusader' is not standard in journals that have an impact factor of 6.7 You'll see that Professor Zehr is a novelist on the side of his academic sports science career.

Now here's a concern for parents as children show worsening fitness over the long-term. The study shows that risk factors for heart disease are prevalent. (see page 1451). Should this type of assessment be part of normal paediatric screening?

BJSM benefits from being part of the $B M J$ family of journals; in this issue we feature two linked papers on knee pain recently published in one of the world's most recognised and influential journals. Read the Scandinavian randomised trial of quality physiotherapy versus arthroscopic partial menisectomy (see page 1473) and the editorial by Finland's Professor Teppo Jarvinen and Canada's founder of evidence-based practice, Professor Gordon Guyatt (see page 1426).
THIS IS ISSUE 23 OF 24 FOR 2016

As BJSM completes its second year with 24 issues we celebrate the opportunity that twice monthly publishing gives us. We are more up to date than we could be with 12 or 18 issues and we can highlight our 23 member societies and their annual conferences. If you want your sports physio or sports medicine community to be a BJSM member society please make contact (karim.khan@ubc.ca).

On this issue's cover you can see the venue for the World Congress on Injury and Illness in Sport from March 16-18 2017-the 'Grimaldi' convention centre in Monaco. Other top conferences in the first half of 2017 include SportsKongress in Copenhagen (February 2-4), The American Medical Society for Sports Medicine in San Diego (May 8-12) and Isokinetic's Football Medicine Strategies in Barcelona (May 13-15). Speakers from these meetings will be featured on the BJSM podcast channel (short conversations, up to 20 minutes); BJSM podcasts are very easy to access using our free mobile app. If you are a sports clinician and haven't checked out the podcasts we recommend you dabble. Our 250 podcasts have had well over 1.1 million listens.

\section{Competing interests None.}

Provenance and peer review Commissioned; internally peer reviewed.

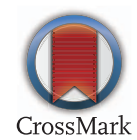

To cite Khan K. Br J Sports Med 2016;50:1425.

Br J Sports Med 2016;50:1425.

doi:10.1136/bjsports-2016-097195 